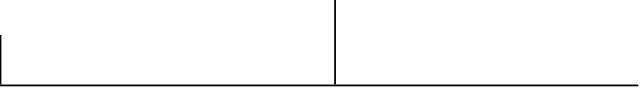

Rev. Latinoam. Psicopat. Fund., São Paulo, v. 14, n. 1, p. 70-82, março 2011

\title{
Das neuroses atuais às neuroses traumáticas: continuidade e ruptura
}

Marta Rezende Cardoso

Analisamos as vicissitudes da neurose traumática, partindo das contribuições de Freud. Propomos uma linha de continuidade considerando também os pontos de ruptura - entre as neuroses traumáticas e as neuroses atuais, a partir de uma releitura da dimensão de "atual" em Freud, articulada com a de compulsão à repetição. Ampliamos a compreensão das neuroses traumáticas por meio da ideia da formação de enclaves no espaço psíquico, exterioridade interna radical que tende a se fazer sempre atual por sua repetição compulsiva.

Palavras-chave: Neuroses traumáticas, neuroses atuais, enclaves, compulsão à repetição 
Em “Além do princípio do prazer" (Freud, 1920), assistimos ao ruidoso retorno do traumático na teoria freudiana. Consideramos, porém, que entre o abandono da teoria traumática da sedução e a emergência de uma nova concepção do trauma nos anos 1920, essa problemática esteve sempre presente na obra de Freud, ainda que latente. Tentar explorar e fundamentar essa formulação constitui o passo inicial da reflexão que oferecemos no presente artigo.

Ao analisar a evolução da teoria e clínica psicanalíticas, observamos que a questão do trauma virá a se desdobrar em duas grandes vertentes, entre as quais há pontos de convergência e de divergência. A primeira vertente resulta na construção de uma teoria traumática da neurose, base dos primeiros escritos de Freud sobre a histeria, cuja etiologia foi suposta como essencialmente traumática. A outra vertente, assentada em elementos bem distintos daqueles da primeira concepção da histeria, ainda que com ela articulada em alguns pontos cruciais, conduzirá, bem mais tarde, à elaboração de uma teoria da neurose traumática cujo quadro sintomático e cujos fundamentos se contrapõem, se assim podemos dizer, aos da neurose propriamente dita.

Formulamos neste ponto, para elaborá-la ao longo do texto, uma questão que julgamos especialmente frutífera numa investigação sobre a singularidade da neurose traumática: seria a neurose traumática uma antineurose?

Como é sabido, com a superação da teoria da sedução, o universo da neurose é ampliado, a fantasia vindo assumir valor de verdade, tendo como um de seus destinos teóricos a conceituação da pulsão. Porém, desde então o eixo do traumático, em sua modalidade tanto constitutiva quanto desestruturante, como afluxo que irrompe e ameaça a integridade egoica - eixo que também consideramos como circunscrevendo o universo da pulsão, neste caso em sua face demoníaca - não será jamais "dissolvido" na teoria; ao contrário, nela deixará resto significativo. E a partir de 1920 a problemática do trauma, mantida "recalcada" no pensamento freudiano desde 1897, neste retornará, com toda força. Isto se deveu, em grande parte, ao confronto da psicanálise com quadros clínicos outros, exteriores à neurose. Freud vem a dirigir seu olhar para patologias marcadas pela ação, no 
mundo interno, de um pulsional disruptivo, sinalizado pelas defesas de tipo radical e elementar acionadas pela compulsão a repetir, destrutivamente, o mesmo.

Contudo, no contexto do novo dualismo pulsional, o ressurgimento do traumático não mais se encontrará com aqueles fundamentos primeiros, traumáticos, das neuroses ditas clássicas, neuroses de transferência. A construção da nova teoria do trauma far-se-á a partir de outras fontes, vindo entrecruzar-se com o postulado de um além do princípio de prazer, na trilha, portanto, da pulsão de morte. Esta nova teoria do trauma é impulsionada, como assinalamos acima, por outra gama de situações clínicas, dentre as quais a neurose traumática tem grande relevo.

Mas faz-se necessário insistir sobre o lugar central que a pulsão ocupa nesses dois universos - o das neuroses de transferência e o das neuroses traumáticas. No nosso entender, seria um grande equívoco supor que a teoria do conflito psíquico, com ênfase na fantasia e no recalcamento - bases da neurose - seria movida por uma dinâmica pulsional, enquanto a base das neuroses traumáticas dela estaria desvinculada, em função do privilégio e peso concedidos à questão do trauma.

Cabe pontuar, como tão bem esclarecem Carvalho e Ribeiro (2006), que não há disjunção entre trauma e pulsão na psicanálise: no novo modelo, o traumático, como efração, revela-se inseparável da ação de uma força pulsional que transgride os limites egoicos. O acontecimento traumático - que pode se apresentar ao sujeito, do exterior, como elemento, como impressão intraduzível - poderia funcionar, em casos singulares, como elemento desencadeador, no espaço interno, da irrupção de um pulsional des-ligado, sem representação ou recalcamento possível, processo correlativo a um estado de desestruturação narcísica. Tratar-se-ia, em última instância, de uma experiência de passividade, de desamparo, cujo protótipo é a própria constituição traumática da subjetividade humana.

\section{Da neurose de angústia à neurose traumática: o excesso e o "atual"}

Ao nos acercarmos da gênese das proposições de "Além do princípio do prazer" (Freud, 1920), observamos que a neurose traumática não deixa de representar, ao menos em parte, uma espécie de curioso desdobramento - como retranscrição profunda operada a posteriori no pensamento freudiano - de algumas das ideias anteriormente apresentadas sobre a neurose de angústia, neurose dita atual. Esta via que, radicalmente transformada, desembocará na teoria da neurose traumática, segue paralela e em contraste com aquela que se inicia pela teoria traumática da neurose, cujo abandono promoveu a abertura e o aprofundamento das neuroses de transferência. A categoria de neurose de angústia, por seu cará- 
ter agudo e atual, se distancia da de neurose de transferência, ainda que Freud não tenha deixado de sugerir, pouco mais à frente, certa relativização dessa contraposição.

Se por meio das neuroses de transferência, Freud, por um lado, descortinará os campos da sexualidade infantil, da pulsão e do recalque, por outro, ao concentrar nelas quase exclusivamente a sua atenção, fará com que o campo do traumático, como mostramos acima, permaneça latente em seu percurso. Só mais tarde, ao dedicar-se ao estudo da neurose traumática cuja marca é a passividade do ego diante de um pulsional não ligado, ele vai reencontrar o campo do traumático, obscurecido até então em sua teorização.

No caso da neurose de angústia, Freud havia sublinhado que a sua etiologia dizia respeito ao acúmulo de excitação sexual que viria se transformar diretamente em angústia, sem mediação psíquica. Não poderíamos inferir que este acúmulo de excitação corresponderia, de fato, a uma insuficiência de elaboração psíquica? Ora, se a excitabilidade geral constituía, nesse momento, a condição essencial da neurose de angústia, Freud parecia já pressentir, em esboço, um dos elementos da concepção de trauma que bem mais tarde irá apresentar, quando do tournant realizado em sua teoria.

No novo modelo o traumático virá a ser identificado com a ação de um excesso pulsional, entendido, mais uma vez, como acúmulo de excitação difícil de ser suportado pelo psiquismo. Como sugerimos acima, eis aqui uma espécie de retranscrição do que tinha sido enunciado como principal característica da neurose de angústia. Quanto à sua origem, Freud a supusera como sendo de natureza sexual. No que concerne à neurose traumática, objeto de sua investigação a partir de 1920, ela resulta de efração, como brecha ampliada, produzida por excesso de energia que vem atacar uma vesícula não preparada. Esta situação de passividade pulsional radical seria seguida de reação de caráter pré-simbólico.

Ao propor este desdobramento, levando em conta, ao mesmo tempo, os pontos de continuidade e de ruptura entre a genealogia da neurose de angústia e a da neurose traumática, cabe ainda pontuar, com Jean Laplanche (1987), que a teoria freudiana da neurose de angústia

... não é uma teoria puramente fisiológica; não é a excitação somática que, simplesmente, não encontra um coito adequado, uma descarga adequada; é, sim, a excitação somática que não encontra seu fiador ao nível psíquico (...), e é ao nível de uma ausência de elaboração que se produz a derivação sob a forma de angústia. (p. 26-27)

Se há aqui alguma escassez, esta seria justamente de libido, como falta de um "fiador" psíquico. Esta leitura do tema permite-nos apreender que a perspectiva freudiana da neurose de angústia, neurose atual, já ultrapassara em muito uma "visão popular", simplista, desta afecção. O que se mostra faltante na neurose atual 
concerne, de fato, à libido psíquica ou, em outros termos, à elaboração psíquica da excitação. E o trabalho psíquico consiste no processo de ligação de uma energia não diferenciada, fazendo com que ela deixe de fluir livremente, permanecendo ligada a certos conteúdos. "A ligação (Bindung) tem, aliás, como correlativo, um processo inverso, que se pode traduzir por 'desligamento' ou 'descarga' (Entbindung), consistindo numa liberação súbita de energia” (Laplanche, 1987, p. 30).

Outro tópico relativo dessa genealogia da neurose traumática - que vem, de uma só vez, transformar e nela trazer os traços da "velha" neurose de angústia, neurose atual - diz respeito à própria dimensão de atualidade. Ao sublinhar o caráter permanente e insistente da angústia nos casos de neurose de angústia, Freud, sem o saber, parecia também vislumbrar, de alguma maneira, a ação daquilo que futuramente tratará como compulsão à repetição. Os repetidos acessos de angústia, próprios à neurose de angústia, haviam sido descritos naquele contexto como vividos desprovidos de conteúdo representativo ou comportando apenas vago conteúdo, como sentimento de aniquilamento, de ameaça, de loucura etc.; estes acessos, de caráter visivelmente disruptivo, estariam ligados, nesse modelo inicial, a um distúrbio sensível ou ao distúrbio de uma função corporal.

A compulsão à repetição, como destino do traumático, destino aquém da representação, não corresponderia, igualmente, a uma retomada, na teoria freudiana, do registro do atual? Mas, a partir de então, este registro ganha novo e radical sentido: o de uma presentificação permanente, que se exerceria pela repetição compulsiva e imperativa da agonia (susto), do desespero, do desamparo, em oposição ao que a angústia propriamente dita, angústia-sinal, seria suscetível de promover em termos de uma preparação.

Embora a questão da repetição há muito estivesse presente em Freud, este conceito também ressurge nesse novo tempo, sob prisma diverso: o da compulsão. Para formular a noção de compulsão à repetição - central em "Além do princípio do prazer", e principal eixo na construção da nova teoria das pulsões -, Freud se viu interrogado por quadros clínicos em que a repetição aparece em primeiro plano. A análise profunda que deles realizou permitiu-lhe repensar também o fenômeno da repetição. Trata-se agora de outra modalidade desta: repetição do mesmo, de caráter, portanto, radical.

Assim, ao longo de toda a história da psicanálise a questão da passividade do ego diante da pulsão, sob seus múltiplos ângulos, permanece aberta e exigindo reflexão. Mas será seguindo a trilha da compulsão à repetição, rumo à pulsão de morte, que se efetivará maior compreensão da questão, por meio desse reencontro com o trauma cujo paradigma passa a ser a neurose traumática. O que faz com que um vivido não seja passível de ser elaborado, isto é, que não seja vinculado ao contexto psíquico, permanecendo, então, como elemento isolado, en- 
cravado como um "fora" no espaço intrapsíquico? Neste ponto é importante lembrar a distinção traçada por Freud entre angústia e susto. Este aponta para um transbordamento do ego e para uma reação cataclísmica. Ora, a ideia de traumatismo leva à de susto: ser atacado de surpresa, sem estar preparado para isso; daí resulta a impossibilidade de elaboração psíquica por parte do ego.

A nova teoria das pulsões tem como pano de fundo, dentre outros fenômenos, os sonhos traumáticos, que indicam a ação de um princípio independente do princípio de prazer, cujo objetivo seria mais primitivo do que o de ter prazer e evitar o desprazer. Esses sonhos constituem a primeira e única exceção à proposição freudiana dos sonhos como realização de desejo. Eles seriam a expressão repetitiva e imperativa desse impedimento de elaboração, ou seja, de interiorização da situação traumática.

A compulsão - Zwang - consiste numa exigência interna de agir, de caráter imperativo e repentino. Por sua vez, esse imediatismo resulta da precariedade dos mecanismos de elaboração psíquica e da impossibilidade de recalcamento. O termo compulsão comporta a ideia de uma pressão inelutável, assim como a de entrave. Quando o aparelho psíquico é atingido por quantidades excessivas de energia pulsional (sem ligação), defesas arcaicas são acionadas como tentativa extrema de manutenção da vida psíquica. Não há aqui o que recordar, somente o que repetir.

\section{Os enclaves na neurose traumática: mensagens antienigmáticas?}

Na neurose traumática a dimensão de atualidade, anteriormente atrelada de maneira restritiva ao contexto das neuroses atuais - e nestas o sentido de atual limitava-se à mera suposição de causalidade -, acaba por readquirir notável densidade. De acordo com a perspectiva que tentamos aqui sugerir, a questão do "atual", ao ser situada no cerne da compulsão à repetição, passa a se referir àqueles elementos, impressões que não conseguem se tornar passado. A violência do traumático concerne à impossibilidade de historicização; por conta disso, a resposta egóica dá-se pela via do ato, resposta fixada, portanto, no registro do "atual" posto que repetidamente presentificada.

A memória traumática tem caráter literal, pois só faz repetir o mesmo; é imemorável, já que nela o passado é presente (Maldonado e Cardoso, 2009). A insistência compulsiva em "presentificar", em "apresentar" o elemento traumático, não passível de representação, constitui o próprio avesso de uma memória representacional. Na neurose traumática, trata-se de uma memória corporal, própria ao tempo do traumático, tempo da urgência, do atual: uma memória, portanto, hiper-real. 
Para se abordar o trauma, é necessário que deixemos em suspenso a questão de saber qual seria a parte de verdade histórica e a de representação fantasmática. Se considerarmos, com Jean Laplanche, que a origem da pulsão não é endógena, mas que se ancora no outro, como mensagem sexual advinda do outro, somos levados, então, a deslocar a questão sobre a realidade externa versus fantasia para a questão de efetividade da mensagem. Assim, caberia examinar o estatuto singular das mensagens que estariam em jogo nas neuroses traumáticas, entendendo que um acontecimento externo, possível desencadeador de um estado traumático, ${ }^{1}$ se apresenta ao sujeito como elemento que se impõe ao seu psiquismo, que o invade qual mensagem, neste caso, mensagem "ultraclara", poder-se-ia dizer, antienigmática.

A categoria de mensagem permite-nos, mais uma vez, superar a dicotomia entre realidade e fantasia. A teoria da sedução generalizada pode vir iluminar não somente o processo de constituição psíquica, necessariamente traumática, mas também as neuroses traumáticas, entendidas aqui, de fato, como estados que nos interrogam sobre um trauma desestruturante.

Como sublinha Korff-Sausse (2001), se nos fixarmos na oposição real/fantasístico, tendemos a recair numa espécie de armadilha. Ao privilegiar nas ditas neuroses traumáticas o papel de elementos, seja de realidade factual, seja de realidade fantasística, acabamos por nos perder na tentativa de tomar uma decisão - decisão, de fato, impossível - sobre o que seria ou não real. Estes dois registros da vida psíquica são absolutamente indissociáveis.

Mas qual seria a singularidade dessas mensagens que advêm do mundo exterior e não conseguem via de simbolização nem de recalcamento? Sobre este ponto, algumas postulações de Claude Barrois (1985) sobre a neurose traumática nos parecem especialmente ricas. Este autor também trata a questão da realidade do traumático, articulando-a estreitamente com a categoria de mensagem. Diz ele:

A neurose traumática do adulto nos oferece a demonstração direta da irredutibilidade do econômico, ante uma mensagem vinda do mundo exterior (na variedade infinita de suas modalidades). De fato é legítimo interrogar-se se a mensagem, em vez de ser enigmática, não é, ao contrário, de uma verdade e de uma clareza absolutas. O enigmático só adviria para encobrir a evidência. (p. 249; tradução nossa)

Ao se romper o sistema paraexcitação, rompe-se também a tela protetora da fantasia, que poderia vir recobrir o terror. Nesses estados traumáticos, as lem-

1. Embora utilizando a denominação "neuroses traumáticas", proposta por Freud, referimo-nos também a essa afecção como estados traumáticos, visando marcar a sua condição transitória e distinta das neuroses de transferência.

Rev. Latinoam. Psicopat. Fund., São Paulo, v. 14, n. 1, p. 70-82, março 2011 
branças não são encobridoras (o que implicaria a ação do recalcamento), e sim literais. Trata-se de uma história não historicizada, o que não se confunde, no entanto, com uma ausência de história. Essa não historicização pressupõe a não interiorização, e conduzirá, como destino, à permanente exteriorização, a uma espécie de tirania do "fora" que se exercerá, entretanto, no interior do espaço psíquico.

Vemo-nos aqui diante da constituição de um "corpo estranho" rebelde, que se contrapõe àquele "corpo estranho" que seria próprio da neurose propriamente dita, neurose de transferência. A recusa aqui é, ao mesmo tempo, de tradução e de des-tradução. Trata-se, portanto, de mensagens imóveis, impossíveis de decompor. Diante de determinadas mensagens, impressões traumáticas, o ego é transbordado, incapaz de integrar ou de recalcar. Para desenvolver essa pista de reflexão propusemos, em outro momento (Cardoso, 2002), estabelecer distinção essencial entre fracasso radical de tradução - fracasso em traduzir - e fracasso parcial de tradução - fracasso de tradução - este último estando na base da constituição do recalcado, aquele na da constituição do "enclavado". É o mais exógeno, o mais "estrangeiro" na mensagem, que vai constituir esses enclaves. Trata-se de mensagens irredutíveis, uma vez que dificilmente suscetíveis de serem conduzidas a outra coisa.

Mais recentemente, Jean Laplanche (2006), instigado pelas proposições de autores que vieram aprofundar certos elementos de sua teoria, elaborando-os num contexto distinto daquele da neurose, reitera a posição que havíamos proposto anteriormente:

O fracasso parcial da tradução dá conta do inconsciente "clássico", neurótico-normal. Ao lado dele, convém dar o devido lugar a um fracasso radical. Nada é traduzido, a mensagem original permanece tal e qual no aparelho psíquico, implantada ou resultando de uma intromissão. Ele constitui então aquilo que se poderia nomear "o inconsciente enclavado". (p. 15; tradução nossa)

A formação dos enclaves não implica deformação recalcante; são mensagens que ficarão "bloqueadas", impossíveis de recalcar ou de substituir por outra coisa. Esses enclaves, portanto, não se apresentam no psiquismo como "representaçõescoisa". Estas perderam sua referência tornando-se "significantes autossignificantes": são os restos da tradução de mensagens enigmáticas. Os enclaves correspondem a um primeiro "depósito de traços" do outro, de impressões traumáticas, índices que tenderão a ressurgir no psiquismo de maneira quase imutável.

Pensar a questão dos estados traumáticos a partir dessa ideia de um fracasso em traduzir - distinta de um fracasso de tradução - não significa, entretanto, que ante uma invasão de forças des-ligadas, não haja ativação de alguma modalidade 
de defesa, mesmo elementar. A compulsão à repetição, mecanismo essencial nas chamadas neuroses traumáticas, apresenta-se como destino possível do traumático, mantendo o sujeito fixado no registro do atual, em um presente que não se faz passado.

Defrontado com a impressão traumática, o ego fica submergido pelo ataque dessa mensagem, no caso, mensagem desprovida justamente da dimensão de "enigma". Esta repetição compulsiva seria, no entanto, uma maneira de "lidar com", de "dominar" as impressões ultraclaras advindas de fora e que se mantêm como um "fora" no mundo interno, como inconsciente enclavado. Aquilo que não pode ser traduzido tende a se repetir como um imperativo, o que em muito difere da condição propriamente neurótica: não se trataria neste caso, portanto, de uma antineurose?

\section{O tempo do a posteriori: "tratamento" psíquico do trauma}

Como indicamos no tópico anterior, a temporalidade própria ao trauma possui um caráter de presentificação. A este respeito, as contribuições de F. Knobloch (1988) sobre o que denomina "tempo do traumático" têm grande interesse, auxiliando o desenvolvimento de nossas ideias.

O tempo do traumático não se temporaliza numa série, é um tempo onde o fascínio é o da ausência de tempo. Ausência de tempo não é um modo negativo: é o tempo em que nada começa, em que a iniciativa não é possível, em que, antes da afirmação, já existe o retorno da firmação (seu fundamento). (p. 123)

Por nossa parte, pensamos que o trauma está referido ao campo de uma memória hiper-real, memória, de fato, imemorável, situada na contracorrente do que seria a construção de uma história. Esta, como uma de suas condições básicas, pressuporia justamente a introdução, ou melhor, a regência, no funcionamento psíquico, da lógica do a posteriori. Por sua vez, como veremos, a possibilidade de um funcionamento baseado nesta lógica depende necessariamente da realização de um "tratamento" psíquico do trauma.

No que diz respeito à clínica dos estados traumáticos, tratar-se-ia justamente da tentativa de abrir esta via como estratégia cuja visada última seria a superação de um estado, na verdade, "antineurótico", com a perspectiva de ir além dele, de ir, portanto, em direção à constituição de um processo, em última instância, neurótico, no sentido estrito do termo.

Uma ilustração pode ser útil neste ponto de nosso percurso. Fazemos menção à situação clínica particular que nos relata Simone Korff-Sausse (2001) em texto no qual aborda a questão do traumatismo vivido por pais de crianças por- 
tadoras de deficiência física. Concordando com a autora, estimamos também que estaríamos, neste caso, diante de uma situação exemplar do que seria um estado traumático, situação que parece nela comportar todos os elementos que caracterizam o trauma. Ou seja, segundo a autora: estado de não preparação do psiquismo; fenômeno que provoca o vivido de "pavor", de agonia, mais do que o de medo ou angústia; situação que pressupõe fracasso da capacidade egoica quanto aos processos de simbolização, e pressupõe, portanto, dominância da ordem do irrepresentável; situação que provoca sideração ou fragmentação da vida psíquica; vivido que escapa ao trabalho egoico de luto, entendido aqui como trabalho do tempo; situação que transborda as possibilidades de metabolização do ego.

Diante desse tipo de vivido - diríamos nós, confrontados com uma mensagem que apresenta uma dimensão ultraclara - sem preparação e, ao mesmo tempo, como acrescenta a autora, "demasiadamente esperado" (por se tratar de acontecimento tão explicitamente temido), esses pais se vêem sob o impacto de forte choque, com suas defesas egoicas pulverizadas. Poder-se-ia aproximá-los, então, dos traumatizados, vítimas de catástrofes naturais ou de guerra.

De acordo com as proposições de Claude Barrois (1985), a etiologia dos estados traumáticos deve pouco ao infantil, a prioridade devendo ser dada à realidade. De nossa parte, tendemos a priorizar, como fator determinante desse estado, o caráter hiper-real, antienigmático, da mensagem que tal acontecimento veicula.

Contrapondo-se às defesas extremas que tendem a ser acionadas no psiquismo de pais quando assolados por esse tipo de mensagem, porém, o tratamento psíquico destas suscitaria, ao contrário, a inserção desses elementos na rede significativa de suas vidas. "O atual deve encontrar lugar e sentido na história do sujeito (...). O presente deve reencontrar o passado para que um futuro seja possível" (Korff-Sausse, 2001, p. 208). A reativação das fantasias anteriores poderia permitir uma via de abertura à significação desse vivido traumático atual.

Numa das vinhetas clínicas que ilustram as ideias desenvolvidas em seu artigo, Korff-Sausse apresenta a história de Madame S., que se sente fortemente culpada do tédio que experimenta ao se ocupar de seu filho deficiente físico, o qual demanda, no entanto, cuidados intensivos. Ao longo do processo terapêutico, a paciente virá a relacionar, no entanto, esse sentimento de tédio com aquele que sentira em sua infância, quando sua mãe a obrigava a se ocupar dos irmãos mais novos. Esta circunstância - e seria preciso considerar aqui outros aspectos que aí estariam implicados - tinha perturbado muito sua infância e, mais tarde, sua adolescência.

Num segundo exemplo, a autora relata a experiência subjetiva de outra mãe de criança com necessidades especiais. Após ter tido outro bebê, este gozando de boa saúde, sente ante ele intenso mal-estar cujo caráter repetitivo é digno de atenção. Se, por um lado, essa mãe se reprova por ter estado anteriormente demasia- 
do ocupada com seu próprio sofrimento de mãe de criança especial, sentindo-se culpada por não ter sido tão atenta e cuidadosa com seu primeiro filho (e não se permitindo desfrutar do prazer de cuidar do novo), ao longo do processo terapêutico, ela vai se dar conta, para além disso, do fato de ela própria ter se representado como criança não desejada de uma mãe que tinha demonstrado intensa dificuldade para dela se ocupar.

Refletindo sobre esses exemplos clínicos, percebemos que é justamente o ingresso do trabalho do après-coup que pode funcionar como via de reinterpretação do passado, permitindo, no plano intrapsíquico, a possibilidade de deslocamento de uma mensagem ultraclara, retirada, assim, de sua condição de enclave. Por intermédio da construção de um elo entre o trauma atual e a neurose infantil do sujeito, tratar-se-ia de restituir a este elemento sua dimensão de enigma. É a construção desse elo, no sujeito, que vai possibilitar - pela ativação de uma memória de representação, em direção à temporalidade do a posteriori - a criação de uma via de passagem de um estado traumático - em outros termos, de uma "antineurose", como estado não processual - a um processo neurótico, no sentido de uma neurose de transferência. Este tem em sua base mensagens submetidas a fracassos de tradução, diferentemente de mensagens que teriam imposto ao aparato psíquico um fracasso de traduzir, não suscetível, em princípio, de "tratamento" psíquico.

Ante à tirania do "atual", do "fora", como exterioridade interna radical, marca interna que só faz se presentificar como memória imemorável, é o acionamento de seu reverso, ou seja, a abertura a uma temporalidade própria ao regime do $a$ posteriori, que poderá, eventualmente, ao entrar em cena, promover, pela instauração de sua própria lógica, a efetiva interiorização de mensagens traumáticas, tornadas assim enigmáticas, passíveis de tradução ou de recalcamento. Uma abertura à neurose propriamente dita?

Agradecimento

A Pedro Henrique Rondon, pela atenta revisão final do texto.

\section{Referências}

BARrois, C. Action du traumatisme, traumatisme en action, action sur le traumatisme. Nouvelle Revue de Psychanalyse, n. 31, p. 239-257, 1985.

CARdoso, M.R. Superego. São Paulo: Escuta, 2002.

Carvalho, M.T.; Ribeiro, P.C. Modelos do trauma em Freud e suas repercussões na psicanálise pós-freudiana. Revista Percurso, n. 37, p. 33-44, $2^{\circ}$ semestre de 2006. 
Freud, S. (1920). Além do princípio do prazer. In: Edição Standard Brasileira das Obras Psicológicas Completas de Sigmund Freud. Rio de Janeiro: Imago, 1974. v. XVIII, p. 13-85.

KNobloch, F. O tempo do traumático. São Paulo: Educ, 1988.

Korff-SAusse, S. Le trauma: de la sidération à la création. In: Marty, F. (Org.). Figures et traitements du traumatisme. Paris: Dunod, 2001. p. 199-222.

Laplanche, J. Problemáticas I - A angústia. São Paulo: Martins Fontes, 1987. . Trois acceptions du mot "inconscient" dans le cadre de la Théorie de la Séduction Généralisée. Psychiatrie Française (Le concept d'inconscient selon Jean Laplanche), v. XXXVII 3/06, n. 9, p. 9-25, novembre 2006.

Maldonado, G.; CARDoso, M.R. O trauma psíquico e o paradoxo das narrativas impossíveis, mas necessárias. Psicologia Clínica, v. 21, n. 1, p. 45-57, 2009.

\section{Resumos}

(From actual neuroses to traumatic neuroses: Continuity and separation)

This article discusses the vicissitudes of traumatic neurosis, based on Freud's contributions. We propose a line of continuity, without ignoring the points of division, between traumatic neuroses and actual neuroses, through a new reading of the dimension of "actual" in Freud, articulated with the notion of the compulsion to repeat. We broaden our understating of traumatic neuroses through the idea of the formation of enclaves, radical inner exteriority, that always tend to be present and "actual" in their compulsive repetition.

Key words: Traumatic neuroses, actual neuroses, enclave, compulsion to repeat

(Des névroses actuelles aux névroses traumatiques: continuité et rupture)

Cet article étudie les vicissitudes de la névrose traumatique en partant des contributions de Freud. Nous proposons la continuité - en tenant aussi compte des points de rupture - entre les névroses traumatiques et les névroses actuelles à partir de la relecture de la dimension de l' "actuel" en Freud, articulée à la compulsion de répétition. Nous élargissons la compréhension des névroses traumatiques en introduisant l'idée de la formation d'enclaves dans l'espace psychique, extériorité interne radicale qui tend à se faire toujours présente et "actuelle" par sa répétition compulsive.

Mots clés: Névroses traumatiques, névroses actuelles, enclaves, compulsion de repétition 
(De las neurosis actuales a las neurosis traumáticas: continuidad y puntos de ruptura)

Este artículo examina las vicisitudes de la neurosis traumática, partiendo de las contribuciones de Freud. Proponemos una línea de continuidad-considerando también los puntos de ruptura - entre las neurosis traumáticas y neurosis actuales, a partir de una relectura de la dimensión de lo "actual" en Freud, articulada con la de compulsión a la repetición. Ampliamos la comprensión de las neurosis traumáticas a través de la idea de formación de enclaves en el espacio psíquico, exterioridad interna radical que tiende a hacerse siempre presente y actual por su repetición compulsiva. Palavras claves: Neurosis traumáticas, neurosis actuales, enclaves, compulsión a la repetición

Citação/Citation: CARDOSO, M.R. Das neuroses atuais às neuroses traumáticas: continuidade e ruptura. Revista Latinoamericana de Psicopatologia Fundamental, São Paulo, v. 14, n. 1, p. 70-82, mar. 2011.

Editor do artigo/Editor: Prof. Dr. Manoel Tosta Berlinck

Recebido/Received: 4.5.2010 / 5.4.2010 Aceito/Accepted: 23.7.2010 / 7.23.2010

Copyright: (C) 2009 Associação Universitária de Pesquisa em Psicopatologia Fundamental/ University Association for Research in Fundamental Psychopathology. Este é um artigo de livre acesso, que permite uso irrestrito, distribuição e reprodução em qualquer meio, desde que o autor e a fonte sejam citados/This is an open-access article, which permits unrestricted use, distribution, and reproduction in any medium, provided the original author and source are credited.

Financiamento/Funding: A autora declara não ter sido financiada ou apoiada/The author has no support or funding to report.

Conflito de interesses/Conflict of interest: A autora declara que não há conflito de interesses/The author declares that has no conflict of interest.

\section{Marta Rezende Cardoso}

Psicanalista; doutora em Psicopatologia Fundamental e Psicanálise - Universidade Denis Diderot - Paris 7 (França); professora Associada do Instituto de Psicologia da Universidade Federal do Rio de Janeiro - UFRJ (Rio de Janeiro, RJ, Brasil) - (Programa de PósGraduação em Teoria Psicanalítica); membro da Associação Universitária de Pesquisa em Psicopatologia Fundamental (São Paulo, SP, Brasil); pesquisadora do CNPq (bolsa de produtividade em pesquisa) (Brasília, DF, Brasil).

Rua Gustavo Sampaio, 710/1805

22010-010 Rio de Janeiro, RJ - Brasil

Fone: (21) 2543-8630

e-mail: rezendecardoso@ig.com.br

rezendecardoso@gmail.com

Rev. Latinoam. Psicopat. Fund., São Paulo, v. 14, n. 1, p. 70-82, março 2011 